\title{
Gordionus chinensis and Gordionus kii sp. nov. (Nematomorpha: Gordiida), New Reports of the Genus Gordionus in Japan
}

\author{
Andreas Schmidt-Rhaesa ${ }^{1}$ and Takuya Sato ${ }^{2}$ \\ ${ }^{1}$ Zoological Museum and Biocenter Grindel, University of Hamburg, \\ Martin-Luther-King-Platz 3, 20146 Hamburg, Germany \\ E-mail: andreas.schmidt-rhaesa@uni-hamburg.de \\ ${ }^{2}$ Kyousei Science Center for Life and Nature, Nara Women's University, \\ Higashimachi, Kitauoya, Nara, 630-8506 Japan \\ E-mail: takuya@species.jp
}

(Received 21 May 2008; Accepted 12 February 2009)

\begin{abstract}
Eleven species representing four genera of freshwater horsehair worms (Gordiida, Nematomorpha) have been known from Japan. The presence of representatives of the genus Gordionus was likely, but until now the available material did not allow such a determination. We here report several specimens of Gordionus chinensis (Villot, 1874) from the Yumitehara River in Nara Prefecture, which differ only in one minute detail from the original description of this species. Characteristic for this species are sparse knoblike structures occurring between the cuticular areoles. In the Japanese specimens, these knobs occur at the midpoint of the common border between pairs of neighbouring areoles and also in the corners where several areoles meet, but in the description of the Chinese holotype, such knobs occur only in the former position. One male specimen from the same locality differs distinctly from the others in having shorter bristles flanking the cloacal opening and longer spines on the inner sides of the tail lobes. We regard it as representing a new species, herein named Gordionus kii.

Key Words: Nematomorpha, Gordiida, horsehair worms, Japan, Nara Prefecture, taxonomy, SEM, new species.
\end{abstract}

\section{Introduction}

Eleven species of freshwater Nematomorpha (Gordiida) have been reported from Japan (Inoue 1955; Fukui and Inoue 1973; Schmidt-Rhaesa 2004; Ichikawa 2007). They are usually found free-living in freshwater habitats, but this constitutes only one phase of their life cycle. During most of their life they live as endoparasites in an assortment of insect species (Hanelt et al. 2005). For Japan, praying mantids are well known as hosts, at least for nematomorph species of the genus Chordodes (Inoue 1962; Schmidt-Rhaesa and Ehrmann 2001; Schmidt-Rhaesa 2004). Most hosts are terrestrial insects and the nematomorphs alter their behaviour and influence them to jump into water (Thomas et al. 2002). Thereby, such parasitized 
terrestrial insects may become prey of fish (Sato et al. 2008).

Schmidt-Rhaesa (2004) reported two female specimens that likely belonged to Gordionus, a genus that had not been reported from Japan before. We now have available a number of male specimens that allow the addition of at least one previously described species, Gordionus chinensis (Villot, 1874), as well as another new species of this genus to the knowledge of the Japanese Nematomorpha. We also report some morphological variation among different specimens of $G$. chinensis.

\section{Material and Methods}

Specimens reported here were all collected by the second author at the same locality, in the Yumitehara River, Totsu River system, Kii Peninsula (Nosegawa village, Yoshino County, Nara Prefecture), on six occasions between August 8 and November 17, 2007. The specimens were fixed in ethanol (70-80\%). Pieces of the cuticle and/or the posterior end were prepared for scanning electron microscopy (SEM). Pieces were dehydrated in an increasing ethanol series, critical point dried, and coated with gold in a sputter coater. Observations took place using a LEO SEM 1524 under $10 \mathrm{kV}$. Digital images were taken.

\section{Taxonomy and Discussion}

\section{Gordionus chinensis (Villot, 1874)}

(Figs 1, 2)

Material examined. Eight males and 3 females, Yumitehara River, Totsu River system, Kii Peninsula, Honshu, Japan (Nosegawa village in Nara Prefecture), 8 Aug.-17 Nov. 2007, coll. T. Sato. One male (V13250) and one female (V13251) are deposited in the Zoological Museum in Hamburg, and two females and seven males (LBM1350000012-LBM1350000020) are in the Lake Biwa Museum, Kusatsu, Shiga Prefecture.

Description. The body colour is medium brown, with some variation. Six specimens were measured, ranging from 79 to $289 \mathrm{~mm}$ in length $(79,84,95,171,224$, and $289 \mathrm{~mm}$ ).

The cuticle is structured into regular, flat areoles, which are polygonal or roundish in shape (Fig. 1A-D). In most specimens, the interareolar space appears to be free of structures at low magnification (Fig. 1B-D), but higher magnification reveals some very short bristles. Between the areoles are sparse knob-like structure (Fig. 1B-D). These are roundish and slightly more elevated than the areoles. They either occur in the corners where three areoles meet (Fig. 1B, circle) or they occur approximately midway along the common border between two areoles (Fig. $1 \mathrm{~B}$, rectangle). This latter pattern has been termed the "megareolar pattern" (Schmidt-Rhaesa 2002). The number of knobs varies. Some specimens show abundant megareolar patterns and fewer knobs in the corners, while in others the knobs in the corners are most abundant and those in megareolar patterns are fewer.

The posterior end is bilobed (Fig. 1E) and the oval to slitlike cloacal opening is 

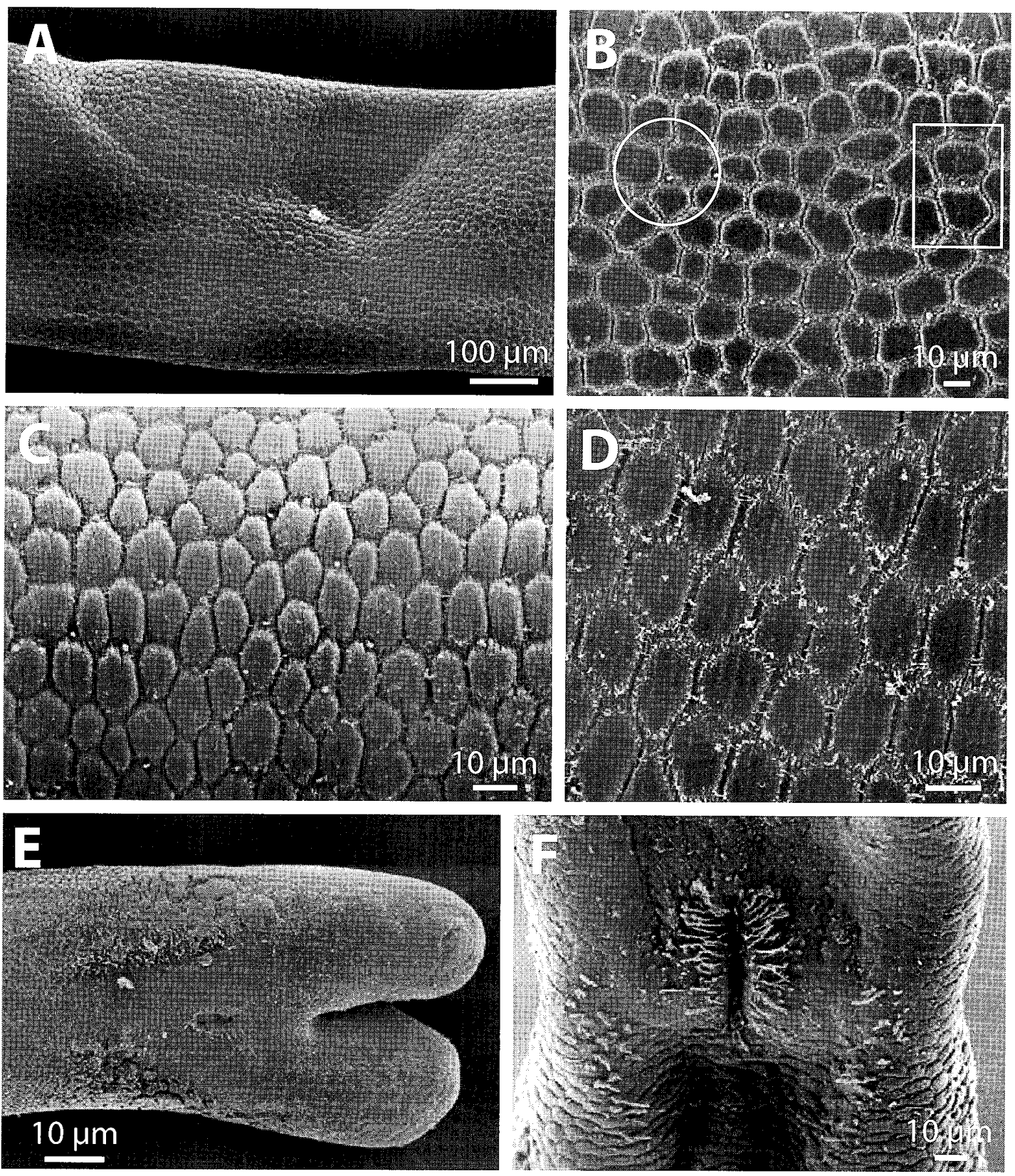

Fig. 1. Gordionus chinensis, SEM photographs of cuticle and male posterior end. A, Overview of cuticle of a female specimen; B, detail of cuticle of a female specimen, showing different patterns of positioning of knobs, either midway along common border between two areoles (rectangle) or in corners where several areoles meet (circle); C, D, cuticle of two further specimens; E, ventral view of posterior end of a male, showing cloacal opening and paired tail lobes; F, detail of cloacal opening with circumcloacal spines.

on the ventral side (Figs 1E, F, 2E). As in other species of Gordionus, there are rows of bristles flanking the cloacal opening laterally and spine-like structures posterior to it, extending onto the inner sides of the tail lobes (Fig. 1E). The cloacal opening is covered with sperm or dirt in some specimens, while in others it is 

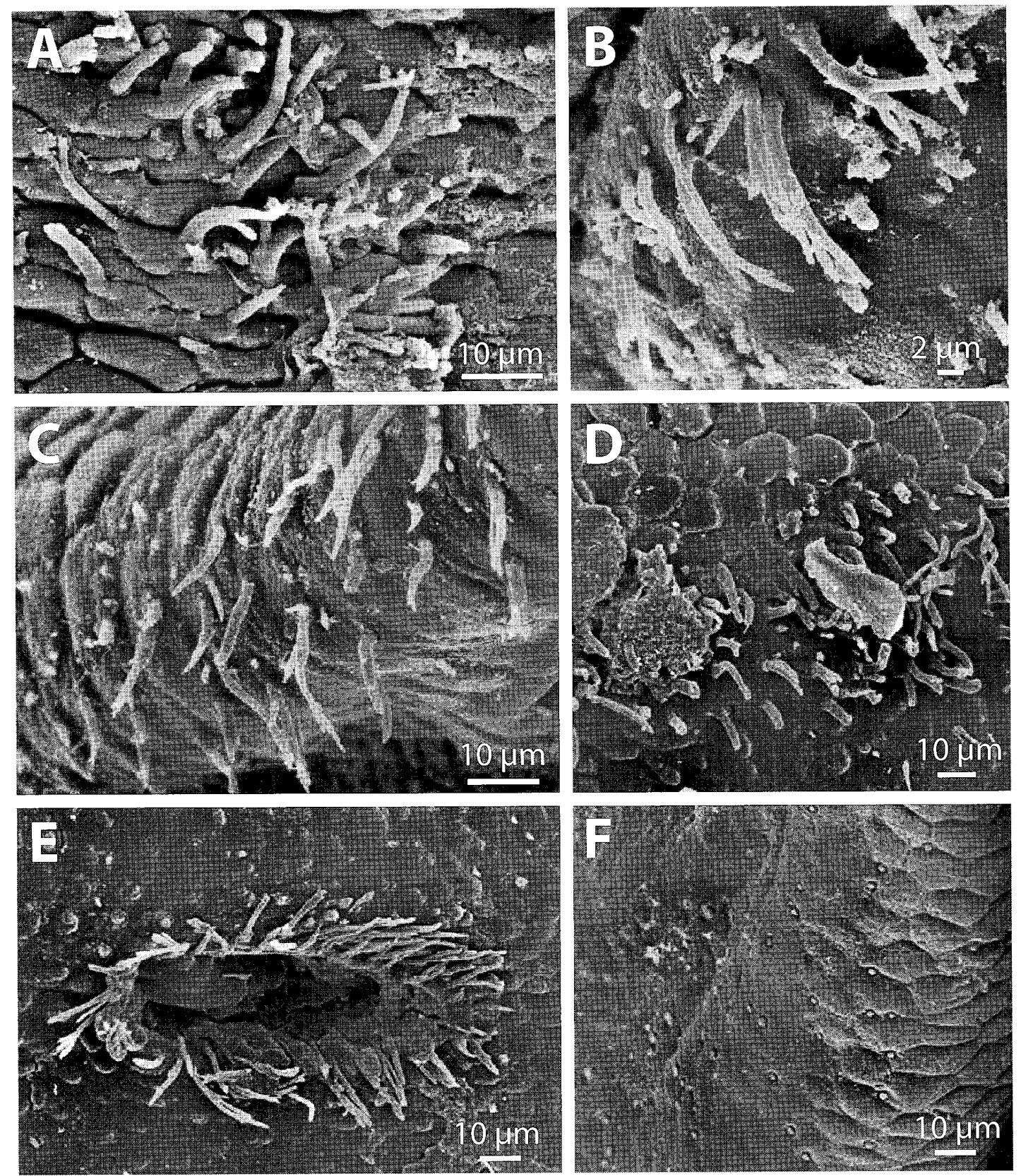

Fig. 2. Gordionus chinensis, SEM photographs of male posterior end. A-D, Bristles of lateral rows flanking cloacal opening in four different specimens; E, cloacal opening with circumcloacal spines; F, small, cone-like spines on inner side of a tail lobe.

clearly surrounded by long, slender spines, the circumcloacal spines (Figs 1F, 2E). Some of these spines are branched apically. The lateral rows of bristles are narrow and consist of comparatively few long and slender bristles (Fig. 2A-D), several of which are branched (Fig. 2A, B). Postcloacal structures include only small conical spines (Fig. 2F).

Discussion. The specimens investigated here show some character variation. 
Almost any single specimen displays a distinctive combination of characters. Because the individual characters vary within a limited range, and because most specimens were collected together, we assume that these differences are expressions of natural morphological variation and that all the present specimens belong to one species. Variation exists in the cuticular pattern, where knobs occur in two positions. The total abundance of knobs and the proportion occurring in each position vary among specimens. The interareolar furrow always contains only a few short bristles. Circumcloacal spines were observed only in some specimens, but in others it is likely that they were covered by sperm. The lateral bristlefields are always narrow and contain comparatively few bristles, a portion of which are always branched. Variation occurs in the length of these bristles; in some specimens they are very short, in others distinctly longer. The postcloacal structures show no variability, always being stout, conical spines.

The description of the present specimens corresponds with that of Gordionus chinensis, first described as Gordius chinensis by Villot (1874) on the basis of a single specimen from China (Peking, now Beijing). Camerano $(1895,1896)$ described four additional specimens from Central Asia and Borneo, but he later transferred these to other species, Parachordodes kaschgaricus Camerano, 1897 and Chordodes weberi (Villot, 1892) (Camerano 1897) and regarded Gordius chinensis as being a "species inquirenda". Dorier (1946) reinvestigated the holotype specimen of Gordius chinensis from Peking, regarded the species as valid, and transferred it to the genus Gordionus. Our specimens correspond in almost all the diagnostic features (shape of circumcloacal and lateral bristles, presence of knobs on the cuticle between areoles, and areoles of only one type). The only difference is that Dorier (1946) only reported knobs along the common border of two areoles. He did not report any knobs from the corners where areoles meet. This might constitute a difference of taxonomic significance between the Chinese and Japanese specimens, but confirmation by a more rigorous reinvestigation of the Chinese holotype using SEM is required.

Gordionus kii sp. nov.

(Fig. 3)

Material examined. Holotype: male, Yumitehara River, Totsu River system, Kii Peninsula, Honshu, Japan (Nosegawa village in Nara Prefecture), 17 September 2007, coll. T. Sato. The holotype (V13252) is deposited in the Zoological Museum in Hamburg.

Description. The body is dark brown and $64 \mathrm{~mm}$ long. The cuticle is structured into regular flat areoles, which are roundish in shape. The surface is structured by superficial furrows (Fig. 3A). The interareolar space contains distinct short bristles surrounding each areole (Fig. 3A). Towards the posterior end, these bristles become sparser (Fig. 3B). Few knob-like structures occur, most of them in the corners where three areoles meet, and only a few in a megareolar pattern (Fig. $3 \mathrm{~A}, \mathrm{~B})$.

The posterior end is bilobed (Fig. 3C). The cloacal opening could not be observed, because it is covered by sperm or dirt (Fig. 3C). The lateral rows of bristles are small and contain only a very few short bristles that rarely exceed $10 \mu \mathrm{m}$ in 

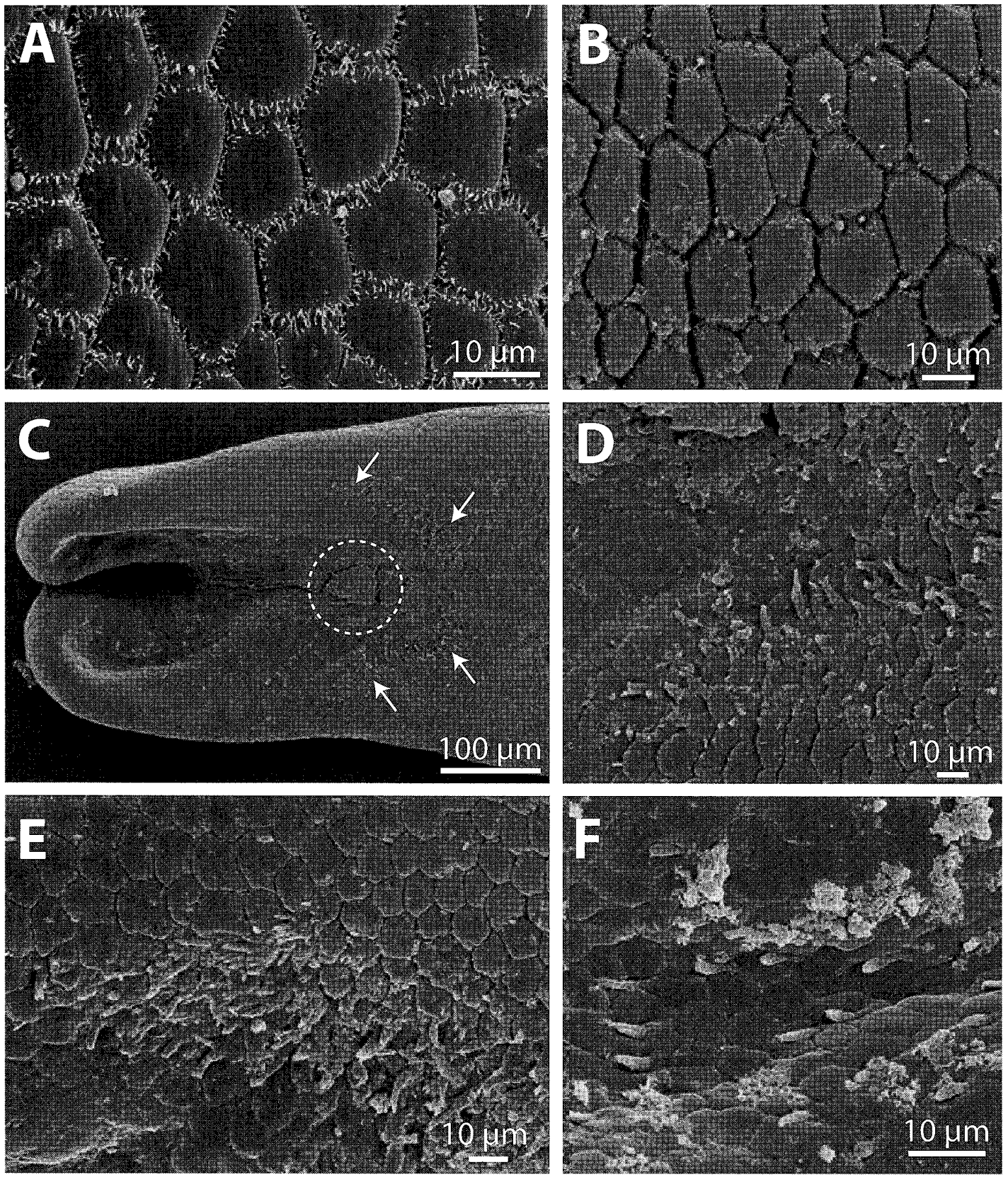

Fig. 3. Gordionus kii sp. nov., holotype, male, SEM photographs of cuticle and posterior end. A, B, Cuticle of different parts of body; C, ventral view of posterior end with cloacal opening covered by sperm or dirt (dashed circle) and positions of lateral rows of bristles (arrows); D, $\mathrm{E}$, structure of bristles in lateral rows; F, elongate spines on inner side of tail lobes.

length (Fig. 3C-E). Most are unbranched, but a few branched bristles are also present. The postcloacal spines are slender and elongate, and about $7 \mu \mathrm{m}$ long (Fig. 3F).

Etymology. The specific epithet is derived from Kii Peninsula where the type locality of the new species is located; noun in the nominative case.

Discussion. Although the holotype was collected at the same place from 
which several specimens determined as Gordionus chinensis were taken, and although we recognize some character variation in the latter species, it differs distinctly from $G$. chinensis in two ways. The bristles in the lateral rows are very short, in contrast to the long bristles of $G$. chinensis, and the postcloacal spines are not conical but slender and elongate. The presence of knob-like structures may indicate some relationship to $G$. chinensis, but we conclude that this specimen represents a distinct species.

\section{Acknowledgements}

We thank Dr Mark J. Grygier for his helpful comments on the manuscript.

\section{References}

Camerano, L. 1895. Gordiens nouveaux ou peu connus du Musée d'Histoire Naturelle de Leyde. Notes from the Leyden Museum 17: 1-14.

Camerano, L. 1896. Gordiens nouveaux ou peu connus du Musée Zoologique de l'Académie Impériale des Sciences de St.Pétersbourg. Annuaire du Musée Zoologique de l’Académie Impériale des Sciences de St. Pétersbourg 1: 117-125.

Camerano, L. 1897. Monografia dei Gordii. Memoire delle Reale Accademia Science di Torino 47: $339-415$.

Dorier, A. 1946. Révision de quelques espèces de Gordiacés. Bulletin du Muséum National d'Histoire Naturelle 18: 480-494.

Fukui, T. and Inoue, I. 1973. Nematomorpha. Pp. 269-271. In: Uéno, M. (Ed.) Freshwater Biology of Japan. Hokuryukan, Tokyo. [In Japanese]

Hanelt, B., Thomas, F. and Schmidt-Rhaesa, A. 2005. Biology of the phylum Nematomorpha. Advances in Parasitology 59: 243-305.

Ichikawa, A. 2007. [A catalogue of the Nematomorpha of Japan]. Battarigisu 140: 12-20. [In Japanese]

Inoue, I. 1955. Synopsis of Japanese Gordiacea, with a note on a new species. Bulletin of the Biogeographical Society of Japan 16-19: 31-35.

Inoue, I. 1962. Studies on the life history of Chordodes japonensis, a species of Gordiacea. III. The mode of infection. Annotationes Zoologicae Japonenses 35: 12-19.

Sato, T., Arizono, M., Sone, R. and Harada, Y. 2008. Parasite-mediated allochthonous input: do hairworms enhance subsidized predation of stream salmonids on crickets? Canadian Journal of Zoology 86: 1-5.

Schmidt-Rhaesa, A. 2002. Are the genera of Nematomorpha monophyletic taxa? Zoologica Scripta 31: 185-200.

Schmidt-Rhaesa, A. 2004. Japanese horsehair worms (Nematomorpha) from the Lake Biwa Museum. Species Diversity 9: 97-107.

Schmidt-Rhaesa, A. and Ehrmann, R. 2001. Horsehair worms (Nematomorpha) as parasites of praying mantids. Zoologischer Anzeiger 240: 167-179.

Thomas, F., Schmidt-Rhaesa, A., Martin, G., Manu, C., Durand, P. and Renaud, F. 2002. Do hairworms (Nematomorpha) manipulate the water-seeking behaviour of their terrestrial hosts? Journal of Evolutionary Biology 15: 356-361.

Villot, M. A. 1874. Monographie des dragonneaux (genre Gordius Dujardin), introduction+ première partie. Taxonomie et histoire naturelle. Archives de Zoologie Expérimentale et Générale 3: 39-72. 